\title{
Classical Musicians \& Copyright in the Digital Age: A Preliminary Investigation
}

\author{
By Kyra Folk-Farber \\ Recipient of the 2013 CAML First-Time Conference Presenter Award
}

\begin{abstract}
Digital technology has greatly increased access to music, both recordings and scores, protected by copyright. A large body of research addresses intellectual property (IP) issues in the recorded music industry, and Diane Parr Walker discusses how American copyright law adversely affects digital music libraries. ${ }^{1}$ However, the use of digitally accessible scores among Canadian classical music professionals remains largely overlooked. This paper provides the background for a research project investigating the relationship between copyright law and Canadian classical musicians in the digital age. The project will use a Canada-wide survey and a series of focus groups to analyze the everyday information-seeking behaviours of classical music professionals and to examine the intellectual property policies that encourage musicians to obey or contravene the law.
\end{abstract}

\section{Introduction}

"Intellectual property disturbs material and epistemological boundaries, recodes existing significations and patterns of information flow, and helps to actualize nascent modes of thought, conduct, affect, expression, and embodiment." ${ }^{2}$

Professional musicians need access to copies of scores to efficiently perform their daily tasks. Because these scores are often costly or out of print, musicians often make copies from music libraries' collections. As more libraries digitize their collections, it will become easier for library members to copy scores.

Through a survey and focus groups, I plan to examine professional Canadian classical musicians' relationship with copyright law. Hopefully this will be a small step in the process of dealing with the copyright implications that come with the imminent digitization of music libraries' score collections.

Kyra Folk-Farber is a Master of Information candidate at the University of Toronto's iSchool, and has a Work Study position at U of T's Music Library. This paper was presented at the 2013 CAML conference, which Kyra attended as the recipient of the CAML First-Time Conference Presenter Award.

1. Dianne Parr Walker, "Music in the Academic Library of Tomorrow," Notes 59, no. 4 (2003): 817-827.

2. Ted Striphas and Kembrew McLeod, "Strategic Improprieties: Cultural Studies, the Everyday, and the Politics of Intellectual Property," Cultural Studies 20, no. 2-3 (2006): 122. 
I will start by analyzing the information-seeking behaviours of this community of professionals; I will then look at the law and policies themselves and consider how changes could benefit musicians.

As a Canadian musician, I have a vested interest in the barriers that copyright law presents. If followed, the law can prevent musicians from doing their day-to-day jobs; individuals are thus left with an uncomfortable choice to make.

Professional musicians need to access musical scores on a daily basis, but the editions they want are often unavailable for purchase, and these must often be back-ordered from manufacturers. Even in a culturally rich city such as Toronto, musicians often have no choice but to order costly scores and then wait weeks or months for cross-border shipping from manufacturers in the US and Germany. Barenreiter's Urtext editions of Mozart operas are an excellent example. Generally agreed to be the most relevant editions, they are difficult and expensive to obtain.

Even if musicians could afford these editions, the items may be too large and heavy to lug from rehearsal to rehearsal. One collaborative pianist is tired of dragging two suitcases of scores to her singing students' competitions so that the company who runs the competition can avoid the "copyright police." In her blog Beyond the Notes, she writes, "I understand them not wanting to get in trouble but I feel like in their effort to be safe, they are making the collaborator's job very trying." ${ }^{3}$

This is, of course, an age-old issue: copyright law is important for intellectual property owners, but this same law presents problems for performers. As an aspiring music librarian, I want to shed light on this situation, to initiate an open conversation about the law and its corresponding policies, and to take on a role as a facilitator among the various stakeholders.

\section{The Role of the Music Librarian}

Ted Striphas and Kembrew McLeod's 2006 article "Strategic Improprieties: Cultural Studies, the Everyday, and the Politics of Intellectual Properties," as well as work by scholars such as William Melody from Aalborg University in Denmark, Tina Piper from McGill, and Laura Murray from Queen's, show that changes to intellectual property policy should be a collaborative process involving not only legal authorities but also knowledge-workers, cultural studies scholars, and performing artists.

Correspondingly, the issue of copyrighted scores concerns librarians, library members, policymakers, vendors, editors, publishers, composers, and related professional associations. As score

3. Erica Ann Sipes, "Copyright Law and Sheet Music: Why It Can Wreak Havoc for an Accompanist/ Collaborator," Beyond the Notes (blog), May 6, 2010, http://ericaannsipes.blogspot.ca/2010/05/copyright-lawand-sheet-music-why-it.html. 
collections are digitized, we should ask about the changing role of the academic music librarian among these stakeholders. Music librarians can inform members of the intellectual property policies within their institutions, of Canadian copyright law, and of the members' rights as these policies and the law evolve. Members can be also directed to external sources of information including associations and government documents. Beyond this, librarians can and arguably have a responsibility to act as advocates to allow members to work without breaking the law. As David Lankes writes in his book The Atlas of New Librarianship, part of librarians' living mission is to "facilitate knowledge creation in their communities." ${ }^{4}$

\section{Literature Review}

Because of developments in digital technology, the issues surrounding citizens' abuse of copyright law have recently become an important source of scholarship. A large body of research addresses intellectual property issues in the recorded music industry. Hip hop, garage band, funk, and other popular genres generate research on topics such as piracy and sampling. However, very little has been written about the illegal use of digitally accessible scores in the classical music community.

This review examines five articles that use distinct theoretical frameworks and research methodologies relevant to an investigation of classical musicians and copyright in the digital age.

In January 2012, the Journal of Hospital Librarianship published a study exploring the informationseeking behaviour of the staff at Metaxa Cancer Hospital in Greece. The authors, Kostagiolas et al., revealed obstacles surrounding the hospital's information needs using a survey. The researchers used a five-point Likert scale to assess respondents' preferences for different information sources for their professional needs.

The article provides a useful description of the researchers' methodology and shows convincing results. However, the resulting data, which showed that the hospital staff were not utilizing their medical library facilities, could have been clarified and enriched with interviews or focus groups.

In "Risk and Freedom for Independent Musicians in Toronto," Brian J. Hracs describes how he conducted 65 interviews to show the risks in their everyday professional lives. Hracs notes their fragmented workspaces, their need to hold down multiple jobs, and their lack of a work community to provide emotional support, explaining that the flexibility and autonomy in musicians' professions increases their financial risk, and that "individuals are being conditioned to make choices according to the imperatives of self-reliance and economic rationality." ${ }^{5}$ Hracs also touches on the changes in spatial dynamics brought on by new technology.

4. R. David Lankes, The Atlas of New Librarianship (Cambridge, MA: MIT Press, 2011): 15.

5. Brian J. Hracs, "Risk and Freedom for Independent Musicians in Toronto," Working Paper Series: Martin Prosperity Research, Martin Prosperity Institute, University of Toronto, Toronto, ON, March 2011, http://martinprosperity.org/papers/Hracs (2011) Risk and Freedom.pdf, 14. 
Hracs' sample population attempts to represent all types of performance careers, ages, and educational backgrounds through snowball sampling, ${ }^{6}$ but his methodology suffers from community bias and inefficient representation. With only 65 interviewees and so many variations within the sample, it is difficult to generalize about some of the categories. For example, seven orchestraemployed musicians are weighed against 24 rock/punk musicians, ${ }^{7}$ and the very distinct kinds of financial risk between these two groups are not addressed. Hracs' investigation of musicians' risk society is thought-provoking. He addresses gaps in the literature that could be filled by convincing research.

Striphas and McLeod's aforementioned article from 2006 discusses the place of cultural studies scholars in the discussion of intellectual property issues. The authors argue that IP law prevents culture from expanding, and that the legal community should not be the sole authority on these issues. They explain that the law is iterative and is sometimes made more flexible, but legal authorities continue to identify themselves as the decision-makers, while people working within the culture are disadvantaged because they are outside the boundaries of the legal sphere. ${ }^{8}$

Striphas and McLeod offer some suggestions for changing the direction of IP discourse to increase the involvement of cultural scholars. For example, they refer to Derrida's satirical essay on copyright $^{9}$ and also discuss how other cultures have established their own traditional, informal systems of protecting intellectual property. ${ }^{10}$ Finally, the authors point out that, as of 2003, professors at many North American universities are allowed to make journal articles freely available to their students, and that these and other "progressive changes were not instituted from the top down through legislation authorized by the law but rather from the ground up by professional societies acting on behalf of their constituents." ${ }^{11}$ Striphas and McLeod's article relies on a theoretical foundation of cultural critique and advocacy, which will anchor my own research study.

In 2005, MacDonald and Wilson studied the psychological process behind improvisation by Scottish jazz musicians. They used two focus groups to find out how jazz musicians perceive themselves within their musical ensembles. The authors write that focus groups give a social context to a study about social understandings, and that "by providing a group context and allowing participants to direct the flow of conversation amongst themselves, the active involvement of the interviewer/researcher (and therefore the influence of their conceptions) can be minimized."12 After explaining what was expected of the participants, the group conversation was initiated with a

6. Hracs, "Risk and Freedom, 15.

7. Ibid., 16.

8. Striphas and McLeod, "Strategic Improprieties," 127.

9. Ibid., 128.

10. Ibid., 129.

11. Ibid., 130.

12. Raymond Macdonald and Graeme Wilson, "Musical Identities of Professional Jazz Musicians: A Focus Group Investigation," Psychology of Music 33, no. 4 (2005): 398. 
quote from a newspaper article by a classical musician. The researchers prompted the discussion with questions only as necessary.

The subjects of this study were Glasgow- and Edinburgh-based jazz instrumentalists for whom performance is a main source of income. The researchers sought a combination of rhythm section players and "front line" players. They did not discuss how they found their participants, but they made it clear that they themselves were familiar with many of the participants, which indicates they used social networking. Their two focus groups comprised five and six musicians. Their participants were almost all male, a fact the authors addressed in their discussion of the results. ${ }^{13}$ The focus group conversations were recorded, and the authors used specific coding methods to find patterns within these conversations. The process MacDonald and Wilson used for their focus groups provides me with a model for the qualitative section of my proposed research.

Dianne Parr Walker's article from 2003, "Music in the Academic Library of Tomorrow," discusses the difficulty of finding musical scores at stores, how the future of scores is digital, and copyright law's potential hindrance of digital music libraries. She predicts that "national and international policies on intellectual property will have a profound effect on whether libraries can legally collect and preserve music in the future. If commercial interests are successful in locking down digital content, libraries will be prohibited from fulfilling their traditional mission. ${ }^{14}$ Walker presents an ideal world of full digital access to copyrighted material, claiming that by working together, knowledge-workers can make this scenario a reality. Walker's article touches on several issues surrounding access to digitized scores in American music libraries' collections. I plan to study how these issues affect music libraries and musicians in Canada.

\section{Research Methodology}

I plan to conduct a mixed methods research study using quantitative data from a large survey and qualitative data from a series of small focus groups. The results of the survey will inform the questions for the focus group discussions.

I hope to survey 150-200 Canadian musicians for whom performance is a main source of income. My sample will represent five major cities and consider gender, age, and a range of professional capacities, including conducting, singing, and playing an instrument. Assuring the subjects' confidentiality is of utmost importance, and I will therefore assign a code to each subject and ensure all survey data is encrypted and stored separately from any identifying information.

13. Macdonald and Wilson, "Musical Identities," 411.

14. Walker, "Music in the Academic Library of Tomorrow," 826. 
The survey will address the following questions:

- How much do professional Canadian classical musicians know about copyright law concerning the use of musical scores?

- Does copyright law help or hinder them in their daily professional tasks?

- How many of the scores they need are available in local academic music library collections?

- Do they make use of that library's digital collection?

Once the survey has assessed the extent of professional Canadian musicians' knowledge of and general opinions on copyright law and their use of digitized scores, I plan to organize three five- or six-person focus groups to gather the stories behind the data. I will contact participants who live in or near Toronto, or who often travel to Toronto, until the focus groups are populated.

I plan to allow the focus group discussions to flow, prompting the participants with questions arising from the survey data. I hope to discover whether the subjects find aspects of the law invalid or irrelevant, and whether as a community, they support each other's choices to ignore or obey the law. I will record and transcribe these discussions, then code and analyze the data.

Confidentiality will be of great concern when conducting the focus groups. Since musicians' careers tend to be eclectic and unique, I will avoid full descriptions of their activities. For example, instead of describing someone as a pianist who also directs a church choir and teaches privately, I will reveal only the activity that applies to the issue under discussion.

I have already conducted an impromptu discussion over lunch with respected colleagues who eagerly contributed their opinions on the topic. The information I gathered makes me confident that focus groups would produce substantial data. I hope to combine this data with the results of the survey to formulate a transparent perspective on Canadian musicians' relationship with copyright law. My ultimate objectives are to shed light on this relationship and to start a conversation about neglected issues concerning intellectual property policy as music libraries' score collections become digitally accessible. 


\section{Bibliography}

Babbie, Earl R. The Practice of Social Research. Belmont, CA: Wadsworth/Thomson Learning, 2007.

Cardell, Vic. “Digital Media Reviews." Notes 58, no. 4 (2002): 889-900.

Case, Donald Owen. Looking for Information: A Survey of Research on Information-Seeking, Needs, and Behavior. San Diego, CA: Academic Press, 2002.

Creswell, John W., and Abbas Tashakkori. "Editorial: Developing Publishable Mixed Methods Manuscripts." Journal of Mixed Methods Research 1 (2007): 107-111.

Dillman, Don A., Jolene D. Smyth, and Leah Melani Christian. Internet, Mail, and Mixed-Mode Surveys: The Tailored Design Method. Hoboken, NJ: Wiley and Sons, 2009.

Fidel, Raya. "Are We There Yet? Mixed Methods Research in Library and Information Science." Library \& Information Science Research 30 (2008): 265-272.

Hracs, Brian J. "Risk and Freedom for Independent Musicians in Toronto." Working Paper Series: Martin Prosperity Research, Martin Prosperity Institute, University of Toronto, Toronto, ON, March 2011. http://martinprosperity.org/papers/Hracs (2011) Risk and Freedom.pdf.

Jenkins, Martin. “Free (Mostly) Scores on the Web." Notes 59, no. 2 (2002): 403-7.

Kostagiolas, Petros A., Katerina Ziavrou, Giorgos Alexias, and Dimitrios Niakas. "Studying the Information-Seeking Behavior of Hospital Professionals: The Case of METAXA Cancer Hospital in Greece." Journal of Hospital Librarianship 12, no. 1 (2012): 33-45.

Lankes, R. David. The Atlas of New Librarianship. Cambridge, MA: MIT Press, 2011.

- New Concepts in Digital Reference. San Rafael, CA: Morgan \& Claypool, 2009.

Lessig, Lawrence. The Future of Ideas: The Fate of the Commons in a Connected World. New York, NY: Random House, 2001.

Macdonald, Raymond, and Graeme Wilson. "Musical Identities of Professional Jazz Musicians: A Focus Group Investigation." Psychology of Music 33, no. 4 (2005): 395-417. 
Sasser, Patricia Puckett. "Sounds of Silence: Investigating institutional Knowledge of the Use and Users of Online Music Collections." Music Reference Services Quarterly 12, no. 3-4 (2009): 93-108.

Striphas, Ted and Kembrew McLeod. "Strategic Improprieties: Cultural Studies, the Everyday, and the Politics of Intellectual Property." Cultural Studies 20, no. 2-3 (2006): 119-44.

Thomas, Charles F. Libraries, the Internet, and Scholarship: Tools and Trends Converging. New York, NY: CRC Press, 2003.

Tillmann-Healy, Lisa M. “Friendship as Method.” Qualitative Inquiry 9, no. 45 (2009): 729-49.

Walker, Diane Parr. "Music in the Academic Library of Tomorrow." Notes 59, no. 4 (2003): 817-27.

Wirtén, Eva Hemmungs. "Out of Sight and Out of Mind: On the Cultural Hegemony of Intellectual Property (critique)." Cultural Studies 20, no. 2-3 (2006): 282-91. 